\title{
A Case Study of Fabry Nephropathy and Its Progression: The First Reported Case in Malaysia
}

Ingrid Ting Pao Lin ( $\nabla$ ingrid_tpl15@hotmail.com )

Miri Hospital https://orcid.org/0000-0002-6476-8073

Andy Tang Sing Ong

Miri Hospital: Hospital Miri

Fam Tem Lom

Miri Hospital: Hospital Miri

Clare Tan Hui Hong

Sarawak General Hospital: Hospital Umum Sarawak

\section{Research Article}

Keywords: Fabry's Disease, case report, Fabry Nephropathy, Enzyme Replacement Therapy, Fabrazyme

Posted Date: February 25th, 2021

DOl: https://doi.org/10.21203/rs.3.rs-230368/v1

License: (c) (1) This work is licensed under a Creative Commons Attribution 4.0 International License. Read Full License 


\section{Abstract}

\section{Introduction}

Fabry disease (FD) is a rare metabolic disorder caused by the genetic deficiency of the lysosomal hydrolase alpha-galactosidase A, causing common and serious kidney complications. We report the first case of Fabry disease detected in Malaysia.

\section{Clinical Scenario}

A 35-year-old man had an incidental finding of proteinuria during routine health screening. His symptoms included frothy urine and intermittent lower limb swelling. Renal biopsy showed features of Fabry's disease which was confirmed with genetic testing. He had classical hemizygous Fabry disease of c.610 C>T with Fabry nephropathy, cardiomyopathy, and cornea verticillata. He was then started on be Enzyme Replacement Therapy (ERT) with agalsidase till date.

\section{Conclusion}

Proteinuria is the predominant factor in Fabry nephropathy predicting renal disease progression rate. Early Fabry Disease diagnosis could prevent kidney disease progression through the timely initiation of treatment which will help enhance the quality of life of the patient, as the disease progresses.

\section{Background}

Fabry Disease (FD) an X-linked lysosomal storage genetic disorder, is caused by deficiency of the agalactosidase A enzyme ( $a-G a l$ A). (1) As a result of the defects in this enzyme, there will be an intralysosomal accumulation of glycospingolids, particularly globotriosylceramide (GL-3) in different cells, plasma and urine leading to renal, cardiac, and cerebral dysfunction and early death. $(2,3)$.

The initial proteinuria in the 20 s and 30 s is among the features of Fabry nephropathy. Among others, there are also features of glomerular sclerosis, tubular atrophy, and interstitial fibrosis. Fabry nephropathy patients may have progressive kidney failure comparable to diabetic nephropathy.(4) Furthermore, Fabry nephropathy is also associated with cardiovascular morbidity and mortality in FD patients.(5) It is estimated that the incidence ranges from 1:40000 to 1:60000 males.(3) The alpha-galactosidase A gene is located on the long arm of chromosome X. Due to its X-linked inheritance, the disease is completely expressed in hemizygous males(3) resulting in the classic form of disease.

\section{Case Presentation}

A 35 year old gentleman, who was a non-smoker and teetotaller, complained of intermittent lower limb swelling and frothy urine since 2009 . He was normotensive and euglycemic with no known family history of kidney disease. Physical examinations were unremarkable. 
Further investigations showed a urine protein dipstick was 2+ with absence of red blood cell or cast under microscopy. His renal profile was normal [initial serum creatinine 63 umol/l, estimated glomerular filtration rate (eGFR) $118 \mathrm{~mL} / \mathrm{min} / 1.73 \mathrm{~m}^{2}$ with the CKD-Epi formula)]. 24-hour urine protein was $1.19 \mathrm{~g} / \mathrm{L}$ with no kidney structural abnormalities being detected by ultrasonography (Right and left kidney sizes measuring $11.3 \mathrm{~cm}$ and $12.0 \mathrm{~cm}$, respectively). The serum albumin was $39 \mathrm{~g} / \mathrm{dl}$ with normal total cholesterol level. He was seronegative for syphilis, human immunodeficiency virus (HIV), Hepatitis B and C. Autoimmune screening was negative.

During follow-up, his proteinuria worsened with 24-hour urine protein rising to $2.8 \mathrm{~g} / \mathrm{L} 4$ years later. $\mathrm{He}$ remained normotensive and euglycemic with no evidence of retinopathy. In view of persistent unexplained proteinuria, renal biopsy (Figure 1) was performed which showed prominent podocytes with expanded abundant cytoplasm that appears pale with fine vacuolation forming lacy appearance. There were also moderate intimal thickening of artery and small foci of tubular atrophy surrounded by interstitial fibrosis seen under microscopy. The immunofluorescence staining for (Ig) $G$, $\lg A$, $\lg M,(C) 3$ and C1q were negative. Hence, FD was highly suspected from the overall findings.

Blood sample for Lysosomal Enzymes Assay Test was subsequently sent. Plasma Alpha-galactosidase A (AGAL) Zero $\mathrm{nmol} / \mathrm{ml} /$ hour (normal reference 2-10). A Genetic study (GLA gene variant Analysis) was conducted based on polymerase chain reaction (PCR) amplification and sequencing methods, confirming the fact that our patient was hemizygous for pathogenic p.Trp204Arg variant (c.610T>C) in the GLA gene, consistent with a final diagnosis of Fabry disease.

Serial system-based physical and ancillary investigations were performed to assess the end-organ involvement of FD. Cornea verticillate were noted in both eyes via slit-lamp examination. Transthoracic echocardiogram showed moderate concentric left ventricular hypertrophy (LVH) with LV ejection fraction above $55 \%$. The other organ systems, including neurology, cutaneous, ears, gastrointestinal tract, cerebrovascular and psychology were unremarkable. Hence, a final diagnosis of FD with renal, ocular, and cardiovascular was made.

He was then commenced on ERT - intravenous Fabrazyme $35 \mathrm{mg}$ two weekly for first two doses, followed by the maintenance regimen $70 \mathrm{mg}(1 \mathrm{mg} / \mathrm{kg})$ every 2 weeks five years after the FD diagnosis was made and almost a decade after his initial presentation. He was also started on low dose Perindopril (a type of angiotensin-converting enzyme ACE inhibitor) for his proteinuria. He remained on these treatments with normal blood pressure to date (approximately two years post ERT commencement). The serial investigation was shown in Table 1.

Table 1: Serial investigation during period of follow-up 


\begin{tabular}{|llllll|}
\hline & $\begin{array}{l}\text { At } \\
\text { presentation } \\
(2009)\end{array}$ & $\begin{array}{l}\text { During } \\
\text { renal } \\
\text { biopsy } \\
\text { (Dec } \\
2013)\end{array}$ & $\begin{array}{l}\text { At initiation } \\
\text { of treatment } \\
\text { (Dec 2018) }\end{array}$ & $\begin{array}{l}\text { At 1 year after } \\
\text { treatment }\end{array}$ & $\begin{array}{l}\text { At } \\
\text { present }\end{array}$ \\
\hline $\begin{array}{l}\text { (Dec 2019) } \\
\text { (g/L) }\end{array}$ & 1.19 & 2.8 & 2.51 & 2.46 & 3.15 \\
\hline $\begin{array}{l}\text { Serum creatinine (umol/L } \\
)\end{array}$ & 63 & 74 & 118 & 164 & 178 \\
\hline $\begin{array}{l}\text { eGFR mL/min/1.73 } \\
\text { m2(CKD-epi formula) }\end{array}$ & 113 & 110.5 & 64.3 & 42.9 & 38.6 \\
\hline
\end{tabular}

His proteinuria showed no improvement despite starting on ERT and kidney function also showed deterioration of $4.3 \mathrm{ml} / \mathrm{min} / 1.73 \mathrm{~m}^{2}$ per year. However, extrarenal manifestation, cardiomyopathy showed improvement, whereby, repeated echocardiogram in 2019 , showed normal left ventricular cavity size and normal wall thickness.

He has 2 younger brothers and 1 younger sister. Enzyme and genetic studies were performed for the siblings using Dry Blood Spot with capillary blood. His younger sister was detected to have FD through the screening with heterozygous mutation of p.Trp204Arg. His mother was also found to have similar mutation.

He has 5 children: 1 son and 4 daughters. His son was tested but was found to be healthy. However, 4 of his daughters were detected to have heterozygous mutation for $\mathrm{p}$.Trp204Arg. This is illustrated in the Figure 2.

\section{Discussion}

Fabry nephropathy is common in Fabry's disease. Typically, Fabry nephropathy is known and likely to start at a young age. Renal biopsies of children and adolescent who had normal eGFR and no proteinuria had exhibited glomerular sclerosis and vascular lesions; $(6,7)$ and glomerular GL-3 have also been detected in foetuses.(8) Our patient had a more severe form of nephropathy where his a-galactosidase levels is $0 \%$ and overt proteinuria at an early age. This is explained by Mahmud et al., where patients with a-galactosidase levels of less than $1 \%$ tends to be more severe. Those with enzyme level detectable the renal involvement is usually less severe and begins late at a mean age of 47 years.(9)

To date more than 900 mutations of agalactosidase gene have been recorded in human mutation database.(10) Most families have private mutations which may explain the variations in clinical presentation of Fabry's disease. The variant both our patient and his family have is a rare heterogenous 
variant of c.610T > C. To date, only 3 occurrences can be found in ClinVar with no detailed clinical information.(11)

In renal biopsy, a typical histopathological lesion is the diagnostic of Fabry Disease. Here Fabry's inclusions can be identified with PAS or Papanicolaou stain demonstrating vacuolated epithelial cells on light microscopy and Maltese cross pattern under polarized light or characteristic lamellar pattern on electron microscopy. (9) This is as shown in the renal biopsy of our patient which showed the all the typical features.

The mainstay of treatment of FD is ERT, and its initiation is recommended in classically affected males and females as soon as early clinical signs of FD occurrence.(12)

For normal population as well as for FD patients, it is a known fact that kidney function decreases with age. $(2,3)$ Nowak et al. found that male FD patients showed a clear decline of kidney function (eGFR) of $3.07 \mathrm{ml} / \mathrm{min} / 1.73 \mathrm{~m}^{2}$ per year over time despite being on ERT. It has also been proposed that male FD patients can pass through several CKD stages ending up with end-stage renal disease within 15 years after the initiation of ERT later in the stage. They also observed that the late initiation of ERT, does not show clear treatment-related benefit on the development of Fabry nephropathy.(13) Our patient was initiated ERT at the age after 35 which is considered late stage and already had significant proteinuria. There are no changes seen in the proteinuria over the years. He had rapid declination in renal function compared to normal population about $4.3 \mathrm{ml} / \mathrm{min} / 1.73 \mathrm{~m}^{2}$ per year but slower declination compared to untreated male FD. Schiffmann et al., reported that for untreated male FD with substantial proteinuria, the rates of renal declination is $6.9 \mathrm{ml} / \mathrm{min} / 1.73 \mathrm{~m}^{2}$ per year(14) while Branton et a/ reported a declination rate of $12 \mathrm{ml} / \mathrm{min} / 1.73 \mathrm{~m}^{2}$ per year.(15)

On the other hand, recent study has found that proteinuria seems to be associated with decreased effectiveness of ERT. $(16,17)$ According to Nowak et al., disease progression was accelerated if ERT patients already had a more severe albuminuria at baseline, similar to this case.(13) This is supported by Wanner $\mathrm{C}$ et al. in which their studies showed that patients with faster progression had significantly higher proteinuria and renal function and men declined more rapidly for those with increased urinary protein levels.(18) However, studies suggest that maximal treatment effect in Fabry nephropathy can be achieved at an early stage with normal or almost normal kidney function. $(19,20)$ This maximal treatment also proved to provide better renal and cardiovascular outcome.(20) ACEi/ARB therapy in conjunction with ERT can reduce proteinuria and stabilize renal function in Fabry patients.(21) Similarly, in this case Perindopril was started for this reason.

In addition to that, another possibility for poor treatment response is the development of neutralizing antibody to ERT. In a study conducted by Linthrost et al., it was found that $69 \%$ of male FD developed Ig G antibodies to agalsidase alpha and beta within 6 months of treatment especially in patient who does not express residual enzyme activity, similar to our patient.(22) And it was also found that once neutralizing antibody had developed, it is irreversible and would stay positive for over 10 years.(23) However, due to 
restricted local resources, the $\lg \mathrm{G}$ antibodies development towards agalsidase beta in the patient was not able to be confirmed. Furthermore, there is no alternative treatment which is currently available for classic male FD with lack of enzyme activity.

Despite the progression of Fabry nephropathy, the treatment of ERT had not been stopped as it was not recommended to stop even in severe renal insufficiency (GFR $<45 \mathrm{ml} / \mathrm{min} / 1.73 \mathrm{~m}^{2}$ ) or those on dialysis or with cognitive decline. It was however carefully considered on an individual basis.(12) As once GFR has been compromised, the goal is reduction and stabilization in the rate of CKD progresses.(24) Furthermore, ERT can reduce the occurrence of major renal, cardiac, and cerebrovascular events. Further reported extra-renal benefits include, for example, decrease in neuropathic pain, improvement of gastrointestinal symptoms, and reduction of left ventricular mass.(4)

\section{Conclusion}

To conclude, Fabry Disease is a rare disease with wide spectrum of clinical manifestations which makes the diagnosing even more difficult for clinicians. Thus, in cases where no apparent causes can be found, high index of suspicion is the key. Proteinuria is the predominant factor in Fabry nephropathy predicting renal disease progression rate. Therefore, an early Fabry Disease diagnosis could prevent kidney disease progression through the timely initiation of treatment which will help enhance the quality of life of the patient, as the disease progresses.

\section{Learning points}

- Fabry Disease is a rare disease with wide spectrum of clinical manifestations

- High index of suspicion in cases where no apparent causes can be found

- Early diagnosis is needed for timely initiation of ERT to enhance quality of life of the patient

\section{Declarations}

\section{Ethical Approval and consent to participate}

This article does contain studies with human participant and was registered via National Medical Research Register, Ministry of Health Malaysia with a registered ID of NMRR-20-1356-55632

\section{Consent for publication}

Written informed consent was obtained from all participants included in the case report

\section{Conflict of Interest}

The authors declare no competing interests

\section{Funding}


The authors declare no financial disclosure

\section{Author's contribution}

IPLT was responsible for the study design, data collection, manuscript writing, ASOT, participated in data collection and contributed to case illustration and discussion. TLF and CHHT were involved in the manuscript editing and language proofreading. All authors read and approved the final manuscript.

\section{Availability of Data and Materials}

The data that support the findings of this study are available from Medical Records Unit, Miri Hospital but restrictions apply to the availability of these data, which were used under special written permission and consent of patients for the current case report, and so are not publicly available. Data are however available from the authors upon reasonable request and with permission of Medical Records Unit, Miri Hospital and Ministry of Health, Malaysia.

\section{Acknowledgment}

The author would like to thank the Director of Health Malaysia and Clinical Research Centre (CRC) Miri Hospital for the permission to publish this paper. We acknowledge Nik Hasimah Binti Nik Yahya for contributing the histopathological (HPE) slide, Dr Koh Keng Hee for co-managing the patient.

\section{References}

1. Desnick R. a-Galactosidase A deficiency: Fabry disease. The metabolic and molecular bases of inherited disease. 2001.

2. Rombach SM, Smid BE, Linthorst GE, Dijkgraaf MG, Hollak CE. Natural course of Fabry disease and the effectiveness of enzyme replacement therapy: a systematic review and meta-analysis. Journal of inherited metabolic disease. 2014;37(3):341-52.

3. Desnick RJ, Brady R, Barranger J, Collins AJ, Germain DP, Goldman M, et al. Fabry disease, an underrecognized multisystemic disorder: expert recommendations for diagnosis, management, and enzyme replacement therapy. Annals of internal medicine. 2003;138(4):338-46.

4. Torra R. Renal manifestations in Fabry disease and therapeutic options: New strategies to prevent cardiovascular risk in chronic kidney disease. Kidney International. 2008;74:S29-S32.

5. Talbot AS, Lewis NT, Nicholls KM. Cardiovascular outcomes in Fabry disease are linked to severity of chronic kidney disease. Heart. 2015;101(4):287-93.

6. Gubler M-C, Lenoir G, Grünfeld J-P, Ulmann A, Droz D, Habib R, et al. Early renal changes in hemizygous and heterozygous patients with Fabry's disease. Kidney international. 1978;13(3):22335 .

7. Tøndel C, Bostad L, Hirth A, Svarstad E. Renal biopsy findings in children and adolescents with Fabry disease and minimal albuminuria. American journal of kidney diseases. 2008;51(5):767-76. 
8. Elleder M, Poupĕtová H, Kozich V. Fetal pathology in Fabry's disease and mucopolysaccharidosis type I. Ceskoslovenska patologie. 1998;34(1):7.

9. Mahmud HM. Fabry's disease-a comprehensive review on pathogenesis, diagnosis and treatment. J Pak Med Assoc. 2014;64(2):189-94.

10. The Human Gene Mutation Database at the Institute of Medical Genetics in Cardiff. [Internet]. [cited 22 August 2020]. Available from: http://www.hgmd.cf.ac.uk/ac/gene.php?gene=GLA

11. Lukas J, Scalia S, Eichler S, Pockrandt AM, Dehn N, Cozma C, et al. Functional and clinical consequences of novel a-galactosidase A mutations in Fabry disease. Human mutation. 2016;37(1):43-51.

12. Biegstraaten M, Arngrímsson R, Barbey F, Boks L, Cecchi F, Deegan PB, et al. Recommendations for initiation and cessation of enzyme replacement therapy in patients with Fabry disease: the European Fabry Working Group consensus document. Orphanet journal of rare diseases. 2015;10(1):36.

13. Nowak A, Koch G, Huynh-Do U, Siegenthaler M, Marti H-P, Pfister M. Disease progression modeling to evaluate the effects of enzyme replacement therapy on kidney function in adult patients with the classic phenotype of Fabry disease. Kidney and Blood Pressure Research. 2017;42(1):1-15.

14. Schiffmann R, Warnock DG, Banikazemi M, Bultas J, Linthorst GE, Packman S, et al. Fabry disease: progression of nephropathy, and prevalence of cardiac and cerebrovascular events before enzyme replacement therapy. Nephrology Dialysis Transplantation. 2009;24(7):2102-11.

15. Branton MH, Schiffmann R, Sabnis SG, Murray GJ, Quirk JM, Altarescu G, et al. Natural history of Fabry renal disease: influence of a-galactosidase $A$ activity and genetic mutations on clinical course. Medicine. 2002;81(2):122-38.

16. Warnock DG, Thomas CP, Vujkovac B, Campbell RC, Charrow J, Laney DA, et al. Antiproteinuric therapy and Fabry nephropathy: factors associated with preserved kidney function during agalsidase-beta therapy. Journal of medical genetics. 2015;52(12):860-6.

17. Warnock DG, Ortiz A, Mauer M, Linthorst GE, Oliveira JP, Serra AL, et al. Renal outcomes of agalsidase beta treatment for Fabry disease: role of proteinuria and timing of treatment initiation. Nephrology Dialysis Transplantation. 2012;27(3):1042-9.

18. Wanner C, Oliveira JP, Ortiz A, Mauer M, Germain DP, Linthorst GE, et al. Prognostic indicators of renal disease progression in adults with Fabry disease: natural history data from the Fabry Registry. Clinical Journal of the American Society of Nephrology. 2010;5(12):2220-8.

19. Tøndel C, Bostad L, Larsen KK, Hirth A, Vikse BE, Houge G, et al. Agalsidase benefits renal histology in young patients with Fabry disease. Journal of the American Society of Nephrology. 2013;24(1):13748.

20. Germain DP, Charrow J, Desnick RJ, Guffon N, Kempf J, Lachmann RH, et al. Ten-year outcome of enzyme replacement therapy with agalsidase beta in patients with Fabry disease. Journal of medical genetics. 2015;52(5):353-8. 
21. Tahir H, Jackson LL, Warnock DG. Antiproteinuric therapy and Fabry nephropathy: sustained reduction of proteinuria in patients receiving enzyme replacement therapy with agalsidase $-\beta$. Journal of the American Society of Nephrology. 2007;18(9):2609-17.

22. Linthorst GE, Hollak CE, Donker-Koopman WE, Strijland A, Aerts JM. Enzyme therapy for Fabry disease: neutralizing antibodies toward agalsidase alpha and beta. Kidney international. 2004;66(4):1589-95.

23. Rombach SM, Aerts JM, Poorthuis BJ, Groener JE, Donker-Koopman W, Hendriks E, et al. Long-term effect of antibodies against infused alpha-galactosidase A in Fabry disease on plasma and urinary (lyso) Gb3 reduction and treatment outcome. PLoS One. 2012;7(10):e47805.

24. De Schoenmakere G, Chauveau D, Grünfeld JP. Enzyme replacement therapy in Anderson-Fabry's disease: beneficial clinical effect on vital organ function. Nephrology Dialysis Transplantation. 2003;18(1):33-5.

\section{Figures}

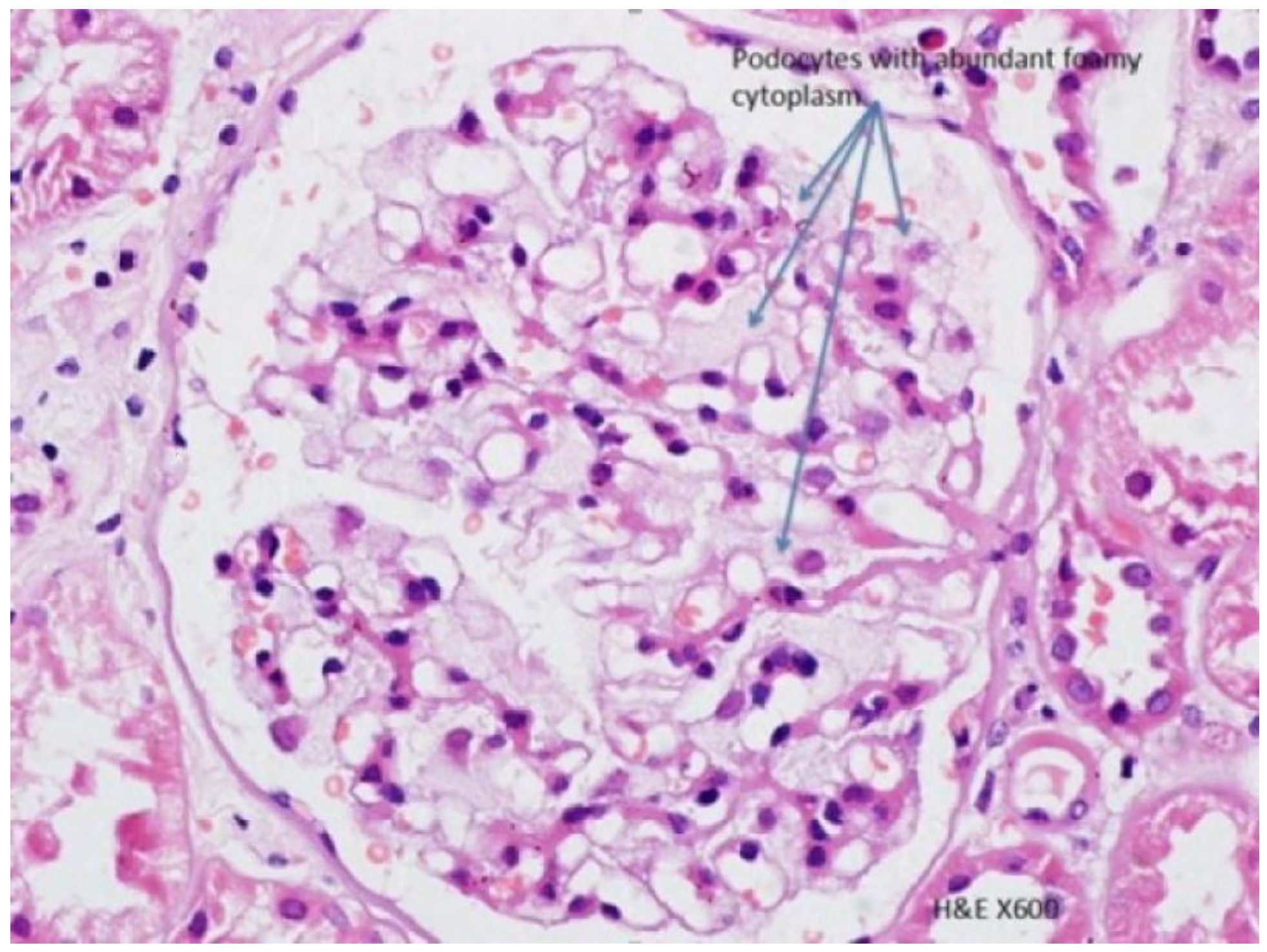


Figure 1

Renal biopsy showing prominent podocytes with abundant foamy cytoplasm
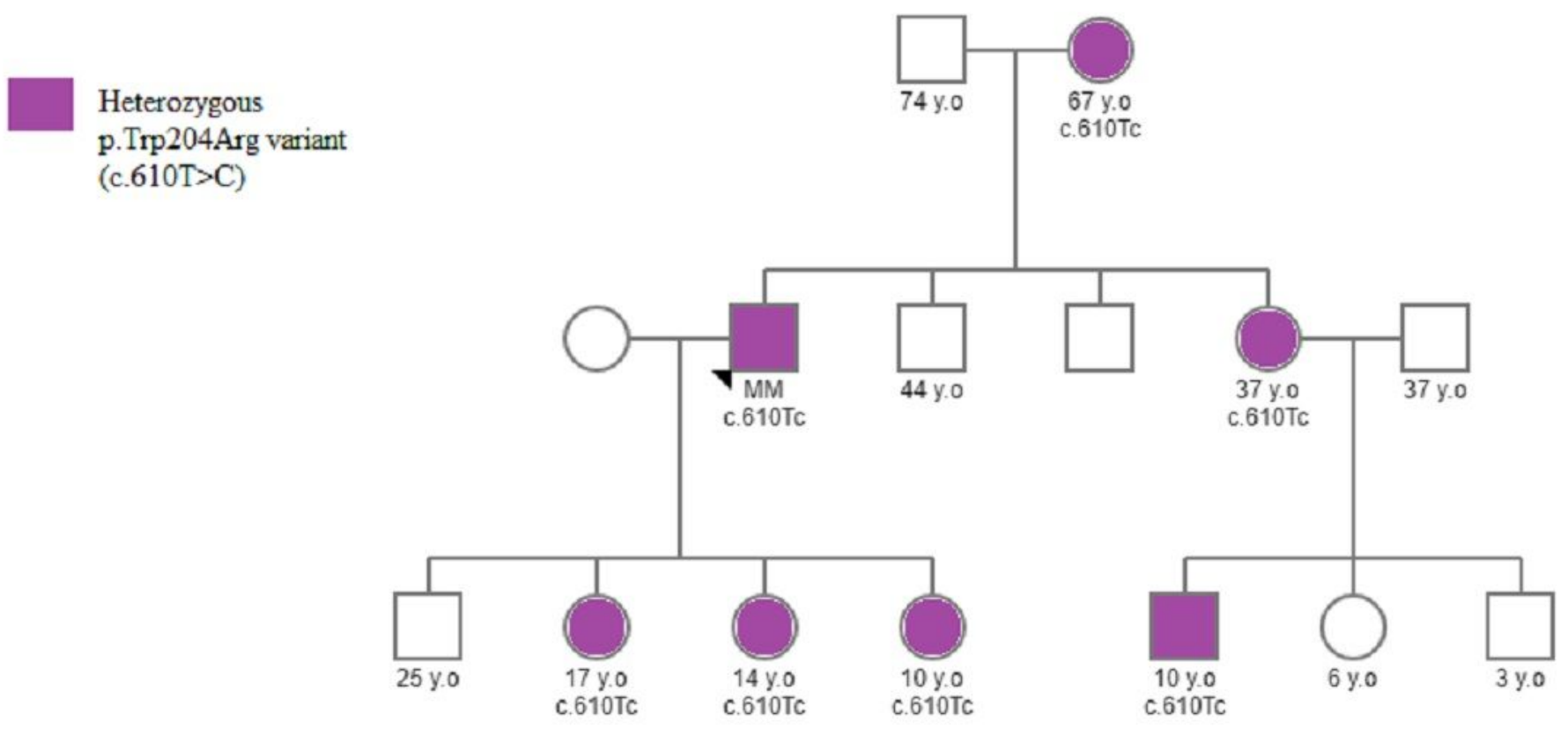

Figure 2

Family tree 